\title{
Dopamine D4 receptor and serotonin transporter gene effects on the longitudinal development of infant temperament
}

\author{
K. Holmboe ${ }^{\star}, \dagger$, , Z. Nemoda§, R. M. P. Fearonף, M. Sasvari-Szekely§, and M. H. Johnson ${ }^{\dagger}$ \\ †Centre for Brain and Cognitive Development, Birkbeck, London, UK \\ ‡MRC Social, Genetic and Developmental Psychiatry Centre, Institute of Psychiatry, King's \\ College London, UK \\ §Department of Medical Chemistry, Molecular Biology and Pathobiochemistry, Semmelweis \\ University, Budapest, Hungary \\ ISchool of Psychology and Clinical Language Sciences, University of Reading, Berkshire, UK
}

\begin{abstract}
Existing studies of the effect on infant temperament of the 48 base pair variable number of tandem repeats polymorphism in exon 3 of the dopamine D4 receptor gene, DRD4 VNTR, and the serotonin transporter-linked polymorphic region, 5-HTTLPR, have provided contradictory results, and age seems to be an important factor. The present study investigated the effect of these two polymorphisms on the stability of infant temperament between 4 and 9 months of age. Furthermore, the effect of a recently discovered single nucleotide polymorphism which modulates the 5-HTTLPR (rs25531) was investigated in relation to infant temperament. The study sample consisted of 90 infants, who were assessed by parental report at the two ages under consideration using the Revised Infant Behavior Questionnaire. It was found that infants carrying the 7-repeat allele of the DRD4 VNTR had higher levels of Negative Affect. Furthermore, there was an interaction between DRD4 VNTR and 5-HTTLPR genotype such that infants with the DRD4 VNTR 7-repeat allele and the highest expressing 5-HTTLPR genotype $\left(\mathrm{L}_{\mathrm{A}} \mathrm{L}_{\mathrm{A}}\right)$ had the highest level of Negative Affect. These effects were largely driven by scores on the Falling Reactivity scale. Genetic effects were stable across age. The results emphasize the need for developmental studies of genetic effects on temperament.
\end{abstract}

\section{Keywords}

5-HTTLPR; DRD4; infant; longitudinal; temperament

Dopamine and serotonin are important neurotransmitters in the brain, which have been linked to normal variation in personality traits as well as to psychiatric disorders.

Dopaminergic genes have been associated with impulsivity, risk-taking behavior, novelty seeking in adolescence and attention deficit hyperactivity disorder / attention problems in childhood (Congdon et al. 2008; Dreber et al . 2009; Eisenberg et al . 2007; Faraone et al .

\footnotetext{
C 2011 Blackwell Publishing Ltd and International Behavioural and Neural Genetics Society

"Corresponding author: K. Holmboe, MRC Social, Genetic and Developmental Psychiatry Centre, Institute of Psychiatry, King's College London, PO Box P080, De Crespigny Park, London SE5 8AF, UK. karla.holmboe@ kcl.ac.uk.

Supporting Information Additional Supporting Information may be found in the online version of this article:

As a service to our authors and readers, this journal provides supporting information supplied by the authors. Such materials are peerreviewed and may be re-organized for online delivery, but are not copy-edited or typeset. Technical support issues arising from supporting information (other than missing files) should be addressed to the authors.
} 
2005; Laucht et al . 2006; Schmidt et al . 2001). Serotonergic genes have been associated with anxiety-related personality traits and affective disorders such as obsessive-compulsive disorder (OCD) and bipolar depression (Anguelova et al . 2003; Bloch et al . 2008; Hu et al . 2006; Lasky-Su et al . 2005; Munafó et al . 2009b; Schinka et al . 2004). Previous studies have also reported associations between temperament traits and dopaminergic and serotonergic gene variants during the first year of life, specifically traits related to attention and negative emotionality. Two polymorphisms in particular have been related to infant temperament, the 48 base pair variable number of tandem repeats in exon 3 of the dopamine D4 receptor gene (DRD4 VNTR), and the serotonin transporter-linked polymorphic region (5-HTTLPR) consisting of a 20-23-base pair imperfect repeat sequence in the promoter region of the serotonin transporter gene (5-HTT, SLC6A4).

Despite these reports, the general picture has been inconsistent and age seems to be an important factor. For example, the presence of the long allele of the DRD4 VNTR has been associated with a more adaptable and less easily distressed temperament in the first 1-2 months of life (Auerbach et al . 1999; De Luca et al . 2001; Ebstein et al . 1998), but this effect seems to disappear later during the first year (De Luca et al . 2001; Lakatos et al . 2003), where, in general, this polymorphism appears to be more associated with attentionrelated aspects of temperament (Auerbach et al . 2001a,b). Likewise, the 5-HTTLPR short/ short genotype has been found to be associated with a higher level of distress at 2 months of age (Auerbach et al . 1999); however, the opposite result was observed in the same group of infants at 12 months of age (Auerbach et al. 2001b). These findings show the inconsistencies in the literature as well as the potentially dynamic nature of genetic effects on temperament during early development. Table 1 provides an overview of previous studies in this area.

Since these early studies, a new functional single nucleotide polymorphism within the 5HTTLPR, rs25531, has been shown to modulate 5-HTT expression (Hu et al . 2006). Traditionally 5-HTTLPR is classified into a lower expressing short allele (S), containing 14 repeat elements, and a higher expressing long allele $(\mathrm{L})$, containing 16 repeat elements (Heils et al . 1996). However, rs25531, which causes a single-base substitution $(A \rightarrow G)$ in the sixth repeat sequence ( $\zeta$ and $\mu$ repeat elements, respectively, after Nakamura et al . 2000), reduces the expression of the $\mathrm{L}$ allele to a level similar to that of the $\mathrm{S}$ allele (Hu et al. 2006). The biallelic classification is therefore no longer sufficient, and recent studies showing effects of 5-HTTLPR on clinical phenotypes such as depression and OCD in adult participants have adopted a triallelic approach (Dannlowski et al. 2007; Hu et al. 2006; Zalsman et al . 2006).

In the present study, we assessed a sample of infants on the same temperament measure at 4 and 9 months of age to address the question of the longitudinal stability of $D R D 4$ VNTR and 5-HTTLPR genetic effects. Given indications in the literature that genotype effects on temperament may be dynamic across early development, the study aimed at identifying whether the effects of these two candidate polymorphisms were stable or changed during the first year of life. In order to use a consistent measurement method, infants were assessed using the Revised Infant Behavior Questionnaire, a well validated parent-report instrument, at the two ages (IBQ-R; Gartstein \& Rothbart 2003). Three broad temperament factors have been identified in previous factor analytic work on the IBQ-R: Surgency/Extraversion, Negative Affect and Orientation/Regulation (Gartstein \& Rothbart 2003). We investigated all three dimensions in relation to the two polymorphisms. A second aim of the present study was to investigate for the first time the impact of rs 25531 , which has been shown to further modulate 5-HTT expression, on infant temperament traits. 


\section{Methods}

One hundred and four infants were recruited for the study. The study was part of a larger longitudinal study investigating frontal cortex functioning and related aspects of development during the first year of life. A detailed description of the study sample is provided in a previous paper (Holmboe et al . 2010). Briefly, infants were recruited from the greater London area through the Babylab volunteer database at the Centre for Brain and Cognitive Development at Birkbeck. Parents were on average in their mid-30s and were primarily, but not exclusively, of middle or upper-middle class socioeconomic status. When the infants were 4 and 9 months old ( \pm 1 week), parents filled in the IBQ-R (Gartstein \& Rothbart 2003). Ninety infants (41 males and 49 females) had temperament ratings from both ages and were included in the analysis. The sample was primarily of White European descent (78.9\% Caucasian, 16.7\% mixed origin, 2.2\% Black and 2.2\% Asian). Ethical permission for the study was obtained from the Department of Psychological Sciences ethics committee at Birkbeck, and all parents were given information about the study and asked to fill in a consent form before participating with their infant.

Buccal cells were used for DNA isolation with a DNA purification kit obtained from Gentra (Minneapolis, MN, USA). Genotyping procedures were carried out using published protocols (DRD4 VNTR: Ronai et al . 2000; 5-HTTLPR with rs25531: Wendland et al . 2006).

In accordance with the factor analysis by Gartstein and Rothbart (2003), a score on each temperament factor was calculated by averaging scores on the scales loading most heavily on that factor (Surgency/Extraversion: Approach, Vocal Reactivity, High Intensity Pleasure, Smiling and Laughter, Activity Level, Perceptual Sensitivity; Negative Affect: Sadness, Distress to Limitations, Fear, and (loading negatively) Falling Reactivity; Orientation/ Regulation: Low Intensity Pleasure, Cuddliness/Affiliation, Duration of Orienting, Soothability, Smiling and Laughter). Cronbach's alpha for each of the IBQ-R scales in the present sample ranged from 0.72 to 0.87 at 4 months and from 0.61 to 0.86 at 9 months (missing values were replaced using the item mean substitution method, see Huisman 2000) and were generally similar to the alpha values reported by Gartstein and Rothbart (2003).

Scores on each of the temperament factors were analyzed using repeated measures analysis of variance (ANOVA). Age (two levels: 4 and 9 months) was the within-subjects factor, and DRD4 genotype (two levels: 7-repeat allele present and 7-repeat allele absent) and triallelic 5-HTTLPR genotype (3 levels: $\mathrm{S}^{\prime} \mathrm{S}^{\prime}, \mathrm{L}^{\prime} \mathrm{S}^{\prime}$ and $\mathrm{L}^{\prime} \mathrm{L}^{\prime}$, recoded as follows based on the presence of the low expression $G$ allele of rs25531: $\mathrm{S}^{\prime} \mathrm{S}^{\prime}$ group $=\mathrm{S}_{\mathrm{A}} \mathrm{S}_{\mathrm{A}}, \mathrm{S}_{\mathrm{A}} \mathrm{S}_{\mathrm{G}}, \mathrm{S}_{\mathrm{A}} \mathrm{L}_{\mathrm{G}}$ and $\mathrm{L}_{\mathrm{G}} \mathrm{L}_{\mathrm{G}} ; \mathrm{L}^{\prime} \mathrm{S}^{\prime}$ group $=\mathrm{S}_{\mathrm{A}} \mathrm{L}_{\mathrm{A}}$ and $\mathrm{L}_{\mathrm{A}} \mathrm{L}_{\mathrm{G}}$; and $\mathrm{L}^{\prime} \mathrm{L}^{\prime}$ group $=\mathrm{L}_{\mathrm{A}} \mathrm{L}_{\mathrm{A}}$ ) were entered as betweensubjects factors. One infant had the unusual $D R D 44 / 8$ genotype and was included in the 7repeat allele present group. Likewise, the 5-HTTLPR 20-repeat allele in one infant was regarded as a long allele. Genotypes were distributed according to Hardy-Weinberg equilibrium (DRD4 VNTR using the most frequent 2-, 3-, 4- and 7-repeat alleles: $\chi^{2}=$ $10.84, \mathrm{df}=6, P=0.09 ; 5$-HTTLPR using the $\mathrm{S}_{\mathrm{A}}, \mathrm{L}_{\mathrm{A}}$ and $\mathrm{L}_{\mathrm{G}}$ alleles: $\chi^{2}=0.28$, $\mathrm{df}=3, P=$ $0.96)$.

\section{Results}

In an initial set of ANOVAS, we established that there were no sex differences in scores on the three IBQ-R factors or any age $\times$ sex interaction (all $P \mathrm{~S}>0.2$ ). In addition, when included in the genotype analyses reported in the following, sex was not a significant covariate and the genotype results were virtually unchanged. 
In analyses involving genotypes and age as independent factors there was a highly significant main effect of age, with older infants scoring higher than younger infants on all three temperament factors $(P<0.001)$. Table 2 presents descriptives for the IBQ-R factor scores at 4 and 9 months of age, and descriptives for each of the IBQ-R scales can be found in Table S1. Table S2 presents descriptives for each IBQ-R scale at 4 and 9 months by DRD4 and 5-HTTLPR genotypes.

In terms of Surgency/Extraversion and Orientation/Regulation, no main effects or interactions involving the DRD4 VNTR or triallelic 5-HTTLPR reached significance (all $P \mathrm{~s}$ $>0.2$ ). However, there was a significant effect of $D R D 4$ genotype on Negative Affect, $F_{1,84}$ $=6.69, P=0.011, \eta_{\mathrm{p}}^{2}=0.074$; infants with the 7-repeat allele scored higher on Negative Affect. The main effect of 5-HTTLPR genotype on Negative Affect was not significant, $F_{2,84}=2.30, P=0.107$, but the interaction between DRD4 and 5-HTTLPR genotypes approached significance, $F_{2,84}=3.05, P=0.053, \eta_{\mathrm{p}}^{2}=0.068$. No interactions between age and genotype reached significance (all $P \mathrm{~S}>0.2$ ), indicating that the genotype effects were stable between 4 and 9 months. The effect of the DRD4 VNTR and triallelic 5-HTTLPR on Negative Affect is illustrated in Fig. 1.

To make sure that the results were not driven by infants of mixed or non-Caucasian ethnic origin, the analysis was rerun using data from Caucasian infants only $(N=71)$. The results were very similar. The main effect of $D R D 4$ genotype was significant, $F_{1,65}=4.53, P=$ $0.037, \eta_{\mathrm{p}}^{2}=0.065$, and the main effect of 5 -HTTLPR genotype was not significant, $F_{2,65}=$ $1.85, P=0.165$. The interaction between $D R D 4$ and $5-H T T L P R$ genotypes in this analysis was significant, $F_{2,65}=3.22, P=0.046, \eta_{\mathrm{p}}^{2}=0.090$. A post hoc analysis with Bonferroni correction, comparing the effect of the 5-HTTLPR polymorphism in each of the two DRD4 genotype groups, indicated that the only significant difference was within the DRD47repeat present group: infants in this group with the 5-HTTLPR $\mathrm{L}^{\prime} \mathrm{L}^{\prime}$ genotype scored higher on the Negative Affect factor than infants with the $S^{\prime} S^{\prime}$ genotype $(P=0.039)$. A second post hoc analysis with Bonferroni correction, comparing the effect of DRD4 genotype in each of the three 5-HTTLPR genotype groups, indicated that infants carrying the 7-repeat allele scored higher on Negative Affect than infants without the 7-repeat allele within the $\mathrm{L}$ ${ }^{\prime} \mathrm{L}^{\prime}(P=0.018)$ and $\mathrm{L}^{\prime} \mathrm{S} '(P=0.023)$ groups, but that this was not the case within the $\mathrm{S}^{\prime} \mathrm{S}{ }^{\prime}$ group $(P=0.4)$. Again, the genotype effects were stable across age (all $P \mathrm{~S}>0.1)$.

To make the results comparable to the infant cohort studied by Auerbach and colleagues (Auerbach et al. 1999, 2001a,b; Ebstein et al . 1998), the data were also analyzed using the long/short $D R D 4$ VNTR categories (short allele: $2-5$ repeats and long allele: 6-8 repeats) and the old 5-HTTLPR categories, i.e., without taking rs25531 into account and dividing genotypes into an SS group and an LS + LL group. The result is included in Table 1 for easy comparison with the previous studies. In this analysis, only the interaction between the $D R D 4$ VNTR and the 5-HTTLPR on Negative Affect reached significance, $F_{1,86}=4.66, P=$ $0.034, \eta_{\mathrm{p}}^{2}=0.051$ (Caucasian subsample: $F_{1,67}=5.72, P=0.020, \eta_{\mathrm{p}}^{2}=0.079$ ). Consistent with the triallelic findings, post hoc tests indicated that within the DRD4 long allele present group infants with the LS + LL genotype scored higher on Negative Affect than infants with the SS genotype $(P=0.008)$, whereas this was not the case in the DRD4 long allele absent group $(P=0.78)$. Likewise, in the LS + LL group infants with the $D R D 4$ long allele scored higher on Negative Affect than infants without the long allele $(P=0.001)$, but this was not the case in the SS group $(P=0.53)$.

Finally, to further explore the genotype effects, each scale comprising the Negative Affect factor was analyzed separately. As results were virtually identical for the total sample and 
the Caucasian subsample in these analyses, only results from the total sample are reported. It turned out that the genetic effects were largely driven by scores on the Falling Reactivity scale. Both the DRD4 VNTR and the 5-HTTLPR had significant effects on this scale (DRD4: $F_{1,84}=6.90, P=0.010, \eta_{\mathrm{p}}^{2}=0.076 ; 5$-HTTLPR: $F_{2,84}=6.96, P=0.002, \eta_{\mathrm{p}}^{2}=0.142$ ) and the interaction was also significant, $F_{2,84}=4.35, P=0.016, \eta_{\mathrm{p}}^{2}=0.094$. These effects are illustrated in Fig. 2 (note that the figure uses reversed scores on the Falling Reactivity scale in order to make the graph comparable to the Negative Affect results presented in Fig. 1; a higher score in Fig. 2 therefore indicates infants who have more difficulty in regulating their affective state).

As with the findings for the Negative Affect factor, the main effect of the DRD4 VNTR was due to the infants in the 7-repeat present group having more problems regulating their affective state, i.e., they had a lower level of Falling Reactivity (although this corresponds to a higher score on the reversed scale used in Fig. 2). In terms of the main effect of the 5$H T T L P R$, a post hoc analysis with Bonferroni correction indicated that infants in the $\mathrm{L}^{\prime} \mathrm{L}{ }^{\prime}$ group had significantly more difficulty in regulating their affective state than infants in the $\mathrm{L}$ ' $\mathrm{S}^{\prime}(P=0.043)$ and $\mathrm{S}^{\prime} \mathrm{S}{ }^{\prime}(P=0.001)$ groups, but there was no significant difference between the $\mathrm{S}^{\prime} \mathrm{S}^{\prime}$ and $\mathrm{L}^{\prime} \mathrm{S}^{\prime}$ groups $(P=0.191)$.

In line with these main effects, a post hoc analysis of the interaction between the DRD4 VNTR and the 5-HTTLPR, specifically comparing the two DRD4 genotype groups, showed that within the DRD47-repeat present group infants with the 5-HTTLPR $\mathrm{L}^{\prime} \mathrm{L}^{\prime}$ genotype had significantly more difficulty in regulating their affective state than infants with the $\mathrm{L}^{\prime} \mathrm{S}^{\prime}(P=$ $0.038)$ and $\mathrm{S}^{\prime} \mathrm{S}^{\prime}(P=0.001)$ genotype; the difference between the $\mathrm{L}^{\prime} \mathrm{S}^{\prime}$ and $\mathrm{S}^{\prime} \mathrm{S}^{\prime}$ groups did not reach significance $(P=0.110)$, and there were no significant differences between 5 $H T T L P R$ genotypes within the DRD47-repeat absent group (all $P \mathrm{~S}>0.2$ ). Conversely, a post hoc analysis with Bonferroni correction comparing the three 5-HTTLPR genotype groups indicated that within the $\mathrm{L}^{\prime} \mathrm{L}^{\prime}$ group infants with the 7-repeat allele had significantly more difficulty in regulating their affective state than infants without the 7-repeat allele $(P=$ $0.002)$. This effect was not seen in the $\mathrm{L}^{\prime} \mathrm{S}^{\prime}$ and $\mathrm{S}^{\prime} \mathrm{S}^{\prime}$ groups $(P>0.1)$.

The Distress to Limitations scale also showed a significant $D R D 4 \times 5$-HTTLPR interaction, $F_{2,84}=3.46, P=0.036, \eta_{\mathrm{p}}^{2}=0.076$. The interaction was similar to that found for the Negative Affect factor. However, associations with the Fear scale were marginal and there were no significant genotype effects on the Sadness scale.

\section{Discussion}

The present study investigated the effect of the DRD4 VNTR and triallelic 5-HTTLPR on infant temperament as assessed by the IBQ-R during the first year of life. No effects were found for the Surgency/Extraversion and Orientation/Regulation factors. This is consistent with previous studies using the IBQ (Auerbach et al . 1999; Lakatos et al . 2003), although studies in newborns and older infants have suggested effects on attention and related aspects of behavior (Auerbach et al . 2001a,b; Ebstein et al . 1998).

The main finding of the present study involved a stable effect of the DRD4 VNTR polymorphism on Negative Affect between 4 and 9 months. According to this result, infants with the 7-repeat allele consistently showed a heightened level of Negative Affect. Previous findings have suggested that very early in infancy (1-2 months of age) the DRD4 long/7repeat allele is associated with an easy temperament and more adaptive behavior (Auerbach et al . 1999; De Luca et al . 2001; Ebstein et al . 1998). The current study suggests the opposite, at least from 4 months onward. These findings emphasize the need for longitudinal 
assessment using the same measures at several time points when investigating genetic effects on temperament in infancy.

The only previous study investigating longitudinal stability in DRD4 VNTR effects on temperament in infancy found an effect of the DRD 4 VNTR on Adaptability at 1 month of age (infants with the 7-repeat allele were more adaptable), but not at 5 months of age (De Luca et al . 2001). A later study of the same children at 3 years of age also did not find an effect of the DRD4 VNTR on Adaptability (De Luca et al. 2003). Taken together these results could be interpreted as suggesting that some discontinuity exists between the $D R D 4$ VNTR effects observed in very early infancy and later during the first year of life. It is also possible that the findings reflect the same effect, but expressed differently at the different ages. For example, infants with the 7-repeat allele may show more alertness and exploration during the first few months (consistent with the findings by Auerbach et al . 1999 and Ebstein et al . 1998), but also more frustration and restlessness later in infancy when confronted with limitations.

The present study also found for the first time an interaction between the $D R D 4$ VNTR and the triallelic 5-HTTLPR polymorphism on infant temperament, with infants who carried both the DRD47-repeat allele and the highest expressing 5-HTTLPR genotype having the highest level of Negative Affect (Fig. 1). Adult studies using the traditional biallelic classification of 5-HTTLPR have shown associations between this polymorphism, anxiety, depression and OCD, although results have been highly contradictory. For example, one meta-analysis of the association between OCD and the 5-HTTLPR suggested that the SS genotype was associated with OCD (Lin 2007), whereas a later meta-analysis suggested that the L allele might be associated with OCD in specific subgroups such as Caucasians and children (Bloch et al . 2008).

Recently, the triallelic 5-HTTLPR classification has been applied to adult studies, and it has been suggested that this may lead to stronger associations between the 5-HTTLPR and the relevant affective phenotypes as a result of the elimination of noise created by previous misclassification of high expressing alleles (Hu et al . 2006; Wendland et al . 2008). Preliminary evidence for this hypothesis comes from studies showing that higher expressing 5-HTTLPR genotypes are associated with OCD and the number of anxiety disorders comorbid with OCD (Hu et al . 2006; Wendland et al . 2007, 2008; but see Voyiaziakis et al. 2011 for a negative result).

Similarly, a wealth of studies has investigated the potential association between the $S$ allele and depression, in particular in the context of stressful life events, which may function as a trigger of depression in individuals carrying the $\mathrm{S}$ allele. Almost all studies investigating this gene $\times$ environment interaction used the biallelic 5-HTTLPR classification, and the existence of this interaction effect is currently under intense debate with many studies confirming the susceptibility to environmental stress of S-allele carriers (Caspi et al . 2010; Uher \& McGuffin 2010), while non-replication has been emphasized in recent metaanalyses (Munafó et al . 2009a; Risch et al. 2009). Again, it is possible that the triallelic 5HTTLPR classification (along with other advances) will help to elucidate this controversy; so far one study has confirmed that the lower expressing genotypes containing the $\mathrm{S}$ or $\mathrm{L}_{\mathrm{G}}$ alleles are associated with depression in the face of stressful life events (Zalsman et al . 2006), and another recent study found that 5-HTTLPR genotype moderated the relationship between childhood emotional abuse and susceptibility to depression in adulthood (as assessed by a measure of cognitive reactivity), such that the $S^{\prime} S^{\prime}$ genotype was particularly sensitive to the childhood environment (Antypa \& Van der Does 2010). 
How these adult studies fit into the infant temperament findings in the current study is not yet clear, especially because relatively little research has been carried out using the triallelic 5-HTTLPR classification. Notably, the effect of the 5-HTTLPR on Negative Affect was only present in the form of an interaction with the DRD4 VNTR. It is interesting however that the interaction was specific to the domain of Negative Affect, given the extensive adult literature which, despite controversies, has linked the 5-HTTLPR to affective disorders and related personality traits. Whether the interactive effects of the triallelic 5-HTTLPR and the $D R D 4$ VNTR are developmentally stable beyond the infant years is therefore an important question for future research.

Previous studies have also found interaction effects between the DRD4 VNTR and 5HTTLPR on infant temperament, but findings have often been contradictory (Table 1). The adoption of the triallelic approach in the present study may have resulted in a more accurate genotype grouping of infants, i.e., infants with $\mathrm{L}_{\mathrm{G}}$ alleles were put into lower expressing 5HTTLPR groups while infants with $\mathrm{L}_{\mathrm{A}}$ alleles were not. Nevertheless, the results were very similar when the traditional biallelic grouping was used (SS vs. LS + LL), suggesting that the findings were robust to different genotype categorizations.

In terms of gene $\times$ environment interaction, the present study was not designed to assess such an interaction. However, it should be noted that our sample had an overrepresentation of mid- and high-socioeconomic status families, and therefore infants were perhaps less likely to experience any serious stressful life events during the study period. This is relevant because S-allele carriers (or carriers of low expressing alleles in the triallelic system) have been hypothesized to be particularly sensitive to stress, with the potential for such exposure to result in affective disorders (Caspi et al . 2010). In the present study, it was in fact the high expressing $\mathrm{L}_{\mathrm{A}}$ allele which, in combination with the $D R D 47$-repeat allele, was associated with more Negative Affect. It is possible that in a sample exposed to adverse life events or simply poorer socioeconomic circumstances, infants with low expressing genotypes would show more affective problems (see Fig. 4A in Caspi et al . 2010 for a graph illustrating the effect of unmeasured environmental exposures in behavioral genetic research). This needs to be tested directly in the future.

When each scale comprising the Negative Affect factor was analyzed separately, the strongest genotype effects were found for the Falling Reactivity scale. According to Gartstein and Rothbart (2003, p. 67), Falling Reactivity is defined as the rate of recovery from peak distress, excitement or general arousal, and reflects the infant's ability to regulate his or her own state. This suggests that the DRD4 and 5-HTTLPR polymorphisms have a particularly strong effect on infant $S^{\prime}$ internal regulation of affect (essentially their ability to calm themselves down) compared with other aspects of negative affect such as sadness. This finding is interesting in light of preliminary evidence that the DRD4 VNTR is associated with infant regulatory problems. Thus, Becker et al. (2007) found that the 7-repeat allele was more prevalent in 3-month-old infant boys with multiple regulatory problems, although the sample was very small. A more recent study by the same group found that in infants with regulatory problems the presence of the 7-repeat allele was associated with a higher risk of developing attention deficit hyperactivity disorder later in childhood (Becker et al . 2010).

In addition to the importance of looking at genotype effects developmentally, it is worth mentioning that there are important examples of measure-specific effects in the adult literature. For example, meta-analyses have found an effect of the 5-HTTLPR specifically on the Neuroticism scale of the revised NEO Personality Inventory (NEO-PI-R), but not on other similar anxiety scales (Munafó et al . 2009b; Schinka et al . 2004). As can be seen from Table 1, a wide range of different measurement instruments have been used in the infant literature, some based on direct observation and some on parent report. The present 
study used the IBQ-R, which has not been used in previous studies (Auerbach et al 1999 and Lakatos et al . 2003 used the IBQ, which has some overlap with the IBQ-R, but scales and many items differ between the two instruments). It is therefore possible that some of the discrepancies in the infant temperament findings are partly due to the differences in measurement instrument. For example, the Falling Reactivity scale, which contributed the most significant result in the present study, is not included in the original IBQ. However, when other Negative Affect scales were based on items included in both the IBQ and IBQ$\mathrm{R}$, the results of the present study were virtually unchanged, suggesting that the genotype effects would have been similar if the IBQ had been used instead of the IBQ-R.

It is worth noting that studies investigating the effects of the 5-HTTLPR on temperament and related constructs later in childhood have also provided mixed results. Some studies have shown that the $\mathrm{S}$ allele is associated with more anxiety/shyness (Battaglia et al . 2005; Hayden et al . 2007), whereas other studies have found the $L$ allele to be associated with these traits (Arbelle et al . 2003; Jorm et al . 2000). As is the case with the infant studies, these studies generally tested children at different ages and used different instruments. Furthermore, a study by Schmidt et al . (2007) found that in the presence of the DRD47repeat allele, the 5-HTTLPR LL genotype appeared to be a protective factor in terms of reducing internalizing and externalizing behavior problems in school-age children. Even though this latter finding might seem contradictory to the findings of the present study where the combination of these two genotypes was associated with the highest level of Negative Affect, it is important to consider the difference in age (infancy and middle childhood) and construct (temperament and behavior problems). To fully understand the trajectory of such genotype effects, longitudinal behavior genetic studies are needed in order to shed light on the relationship between temperamental differences early in life and later outcomes (e.g., behavior problems).

The present study is limited in terms of its small sample size $(N=90)$. The findings therefore need to be independently replicated before any firm conclusions can be drawn. This is especially true for the DRD4 VNTR $\times 5$-HTTLPR interaction, as gene $\times$ gene interaction effects have often been inconsistent (Table 1). Eventually, the effect of candidate polymorphisms on infant temperament should also be subjected to a meta-analysis in order to establish the existence and true size of these effects. Having said that, compared with the adult literature, the infant literature on the effect of candidate polymorphisms on temperament and related traits is relatively small, with only a few independent cohorts being studied (De Luca et al . 2001; Ebstein et al . 1998; Lakatos et al . 2003; present study). The finding of longitudinal stability in the effects of the DRD4 and 5-HTTLPR polymorphisms on temperament during the first year of life, as assessed by the same well validated questionnaire, is an important addition to this literature. Future studies should assess temperament in a larger group of infants, following them up into the childhood years and ideally using highly similar measures across time to assess both measure-specific and developmental effects.

\section{Supplementary Material}

Refer to Web version on PubMed Central for supplementary material.

\section{Acknowledgments}

The work reported in this article was supported by the UK Medical Research Council (Program Grant G9715587, P.I. Professor Johnson) and the Hungarian Scientific Research Fund, OTKA (Grant T048576, P.I. Professor Sasvari-Szekely). The first author was supported by a postdoctoral fellowship from the UK Medical Research Council and the UK Economic and Social Research Council (Fellowship No. G0800054). The authors would like to thank the parents and children who made this work possible by participating in the study. This article is dedicated to 
my daughter Matilda Holmboe Wiltshire who died from Langerhans cell histiocytosis on 23rd February 2011 at the age of $5 \frac{1}{2}$ months. Matilda showed incredible strength and cheerfulness through the hardest of times. She was so loved and will never be forgotten.

\section{References}

Anguelova M, Benkelfat C, Turecki G. A systematic review of association studies investigating genes coding for serotonin receptors and the serotonin transporter: I. Affective disorders. Mol Psychiatry. 2003; 8:574-591. [PubMed: 12851635]

Antypa N, Van der Does AJW. Serotonin transporter gene, childhood emotional abuse and cognitive vulnerability to depression. Genes Brain Behav. 2010; 9:615-620. [PubMed: 20455953]

Arbelle S, Benjamin J, Golin M, Kremer I, Belmaker RH, Ebstein RP. Relation of shyness in grade school children to the genotype for the long form of the serotonin transporter promoter region polymorphism. Am J Psychiatry. 2003; 160:671-676. [PubMed: 12668354]

Auerbach J, Geller V, Lezer S, Shinwell E, Belmaker RH, Levine J, Ebstein RP. Dopamine D4 receptor (D4DR) and serotonin transporter promoter (5-HTTLPR) polymorphisms in the determination of temperament in 2-month-old infants. Mol Psychiatry. 1999; 4:369-373. [PubMed: 10483054]

Auerbach JG, Benjamin J, Faroy M, Geller V, Ebstein R. DRD4 related to infant attention and information processing: a developmental link to ADHD? Psychiatr Genet. 2001a; 11:31-35. [PubMed: 11409697]

Auerbach JG, Faroy M, Ebstein R, Kahana M, Levine J. The association of the dopamine D4 receptor gene (DRD4) and the serotonin transporter promoter gene (5-HTTLPR) with temperament in 12month-old infants. J Child Psychol Psychiatry. 2001b; 42:777-783. [PubMed: 11583250]

Battaglia M, Ogliari A, Zanoni A, Citterio A, Pozzoli U, Giorda R, Maffei C, Marino C. Influence of the serotonin transporter promoter gene and shyness on children's cerebral responses to facial expressions. Arch Gen Psychiatry. 2005; 62:85-94. [PubMed: 15630076]

Becker K, El-Faddagh M, Schmidt MH, Laucht M. Dopaminergic polymorphisms and regulatory problems in infancy. Z Kinder Jugendpsychiatr Psychother. 2007; 35:145-151. (in German). [PubMed: 17608284]

Becker K, Blomeyer D, El-Faddagh M, Esser G, Schmidt MH, Banaschewski T, Laucht M. From regulatory problems in infancy to attention-deficit/hyperactivity disorder in childhood: a moderating role for the dopamine D4 receptor gene? J Pediatr. 2010; 156:798-803. [PubMed: 20172533]

Bloch MH, Landeros-Weisenberger A, Sen S, Dombrowski P, Kelmendi B, Coric V, Pittenger C, Leckman JF. Association of the serotonin transporter polymorphism and obsessive-compulsive disorder: systematic review. Am J Med Genet. 2008; 147B:850-858. [PubMed: 18186076]

Caspi A, Hariri AR, Holmes A, Uher R, Moffitt TE. Genetic sensitivity to the environment: the case of the serotonin transporter gene and its implications for studying complex diseases and traits. Am J Psychiatry. 2010; 167:509-527. [PubMed: 20231323]

Congdon E, Lesch KP, Canli T. Analysis of DRD4 and DAT polymorphisms and behavioral inhibition in healthy adults: implications for impulsivity. Am J Med Genet. 2008; 147B:27-32. [PubMed: 17525955]

Dannlowski U, Ohrmann P, Bauer J, Kugel H, Baune BT, Hohoff C, Kersting A, Arolt V, Heindel W, Deckert J, Suslow T. Serotonergic genes modulate amygdala activity in major depression. Genes Brain Behav. 2007; 6:672-676. [PubMed: 17284168]

De Luca A, Rizzardi M, Torrente I, Alessandroni R, Salvioli GP, Filograsso N, Dallapiccola B, Novelli G. Dopamine D4 receptor (DRD4) polymorphism and adaptability trait during infancy: a longitudinal study in 1- to 5-month-old neonates. Neurogenetics. 2001; 3:79-82. [PubMed: 11354829]

De Luca A, Rizzardi M, Buccino A, Alessandroni R, Salvioli GP, Filograsso N, Novelli G, Dallapiccola B. Association of dopamine D4 receptor (DRD4) exon III repeat polymorphism with temperament in 3-year-old infants. Neurogenetics. 2003; 4:207-212. [PubMed: 12687422]

Dreber A, Apicella C, Eisenberg D, Garcia J, Zamore R, Lum J, Campbell B. The 7R polymorphism in the dopamine receptor $\mathrm{D}_{4}$ gene (DRD4) is associated with financial risk taking in men. Evol Hum Behav. 2009; 30:85-92. 
Ebstein RP, Levine J, Geller V, Auerbach J, Gritsenko I, Belmaker RH. Dopamine D4 receptor and serotonin transporter promoter in the determination of neonatal temperament. Mol Psychiatry. 1998; 3:238-246. [PubMed: 9672899]

Eisenberg DTA, MacKillop J, Modi M, Beauchemin J, Dang D, Lisman SA, Lum JK, Wilson DS. Examining impulsivity as an endophenotype using a behavioral approach: a DRD2 TaqI A and DRD4 48-bp VNTR association study. Behav Brain Funct. 2007; 3 http:// www.behavioralandbrainfunctions.com/content/3/1/2.

Faraone SV, Perlis RH, Doyle AE, Smoller JW, Goralnick JJ, Holmgren MA, Sklar P. Molecular genetics of attention-deficit/hyperactivity disorder. Biol Psychiatry. 2005; 57:1313-1323. [PubMed: 15950004]

Gartstein MA, Rothbart MK. Studying infant temperament via the Revised Infant Behavior Questionnaire. Infant Behav Dev. 2003; 26:64-86.

Hayden EP, Dougherty LR, Maloney B, Durbin CE, Olino TM, Nurnberger JI Jr, Lahiri DK, Klein DN. Temperamental fearfulness in childhood and the serotonin transporter promoter region polymorphism: a multimethod association study. Psychiatr Genet. 2007; 17:135-142. [PubMed: 17417056]

Heils A, Teufel A, Petri S, Stöber G, Riederer P, Bengel D, Lesch K. Allelic variation of human serotonin transporter gene expression. J Neurochem. 1996; 66:2621-2624. [PubMed: 8632190]

Holmboe K, Nemoda Z, Fearon RMP, Csibra G, Sasvari-Szekely M, Johnson MH. Polymorphisms in dopamine system genes are associated with individual differences in attention in infancy. Dev Psychol. 2010; 46:404-416. [PubMed: 20210499]

Hu XZ, Lipsky RH, Zhu G, Akhtar LA, Taubman J, Greenberg BD, Xu K, Arnold PD, Richter MA, Kennedy JL. Serotonin transporter promoter gain-of-function genotypes are linked to obsessivecompulsive disorder. Am J Hum Genet. 2006; 78:815-826. [PubMed: 16642437]

Huisman M. Imputation of missing item responses: some simple techniques. Qual Quant. 2000; 34:331-351.

Jorm AF, Prior M, Sanson A, Smart D, Zhang Y, Easteal S. Association of a functional polymorphism of the serotonin transporter gene with anxiety-related temperament and behavior problems in children: a longitudinal study from infancy to the mid-teens. Mol Psychiatry. 2000; 5:542-547. [PubMed: 11032389]

Lakatos K, Nemoda Z, Birkas E, Ronai Z, Kovacs E, Ney K, Toth I, Sasvari-Szekely M, Gervai J. Association of D4 dopamine receptor gene and serotonin transporter promoter polymorphisms with infantS' ${ }^{\prime}$ response to novelty. Mol Psychiatry. 2003; 8:90-97. [PubMed: 12556912]

Lasky-Su JA, Faraone SV, Glatt SJ, Tsuang MT. Meta-analysis of the association between two polymorphisms in the serotonin transporter gene and affective disorders. Am J Med Genet. 2005; 133B:110-115. [PubMed: 15578606]

Laucht M, Becker K, Schmidt MH. Visual exploratory behaviour in infancy and novelty seeking in adolescence: two developmentally specific phenotypes of DRD4? J Child Psychol Psychiatry. 2006; 47:1143-1151. [PubMed: 17076753]

Lin P-Y. Meta-analysis of the association of serotonin transporter gene polymorphism with obsessivecompulsive disorder. Prog Neuropsychopharmacol Biol Psychiatry. 2007; 31:683-689. [PubMed: 17291658]

Munafò MR, Durrant C, Lewis G, Flint J. Gene $\times$ environment interactions at the serotonin transporter locus. Biol Psychiatry. 2009a; 65:211-219.

Munafò MR, Freimer NB, Ng W, Ophoff R, Veijola J, Miettunen J, Järvelin MR, Taanila A, Flint J. 5HTTLPR genotype and anxiety-related personality traits: a meta-analysis and new data. Am J Med Genet. 2009b; 150B:271-281.

Nakamura M, Ueno S, Sano A, Tanabe H. The human serotonin transporter gene linked polymorphism (5-HTTLPR) shows ten novel allelic variants. Mol Psychiatry. 2000; 5:32-38. [PubMed: 10673766]

Risch N, Herrell R, Lehner T, Liang K-Y, Eaves L, Hoh J, Griem A, Kovacs M, Ott J, Merikangas $\mathrm{KR}$. Interaction between the serotonin transporter gene (5-HTTLPR), stressful life events, and risk of depression: a meta-analysis. JAMA. 2009; 301:2462-2471. [PubMed: 19531786] 
Ronai Z, Guttman A, Nemoda Z, Staub M, Kalasz H, Sasvari-Szekely M. Rapid and sensitive genotyping of dopamine D4 receptor tandem repeats by automated ultrathin-layer gel electrophoresis. Electrophoresis. 2000; 21:2058-2061. [PubMed: 10879966]

Schinka J, Busch R, Robichaux-Keene N. A meta-analysis of the association between the serotonin transporter gene polymorphism (5-HTTLPR) and trait anxiety. Mol Psychiatry. 2004; 9:197-202. [PubMed: 14966478]

Schmidt LA, Fox NA, Perez-Edgar K, Hu S, Hamer DH. Association of DRD4 with attention problems in normal childhood development. Psychiatr Genet. 2001; 11:25-29. [PubMed: 11409696]

Schmidt LA, Fox NA, Hamer DH. Evidence for a gene-gene interaction in predicting children's behavior problems: association of serotonin transporter short and dopamine receptor D4 long genotypes with internalizing and externalizing behaviors in typically developing 7-year-olds. Dev Psychopathol. 2007; 19:1105-1116. [PubMed: 17931437]

Uher R, McGuffin P. The moderation by the serotonin transporter gene of environmental adversity in the etiology of depression: 2009 update. Mol Psychiatry. 2010; 15:18-22. [PubMed: 20029411]

Voyiaziakis E, Evgrafov O, Li D, et al. Association of SLC6A4 variants with obsessive-compulsive disorder in a large multicenter US family study. Mol Psychiatry. 2011; 16:108-120. [PubMed: 19806148]

Wendland J, Moya P, Kruse M, Ren-Patterson R, Jensen C, Timpano K, Murphy D. A novel, putative gain-of-function haplotype at SLC6A4 associates with obsessive-compulsive disorder. Hum Mol Genet. 2008; 17:717-723. [PubMed: 18055562]

Wendland JR, Martin BJ, Kruse MR, Lesch K-P, Murphy DL. Simultaneous genotyping of four functional loci of human SLC6A4, with a reappraisal of 5-HTTLPR and rs25531. Mol Psychiatry. 2006; 11:224-226. [PubMed: 16402131]

Wendland JR, Kruse MR, Cromer KC, Murphy DL. A large case-control study of common functional SLC6A4 and BDNF variants in obsessive-compulsive disorder. Neuropsychopharmacology. 2007; 32:2543-2551. [PubMed: 17375136]

Zalsman G, Huang YY, Oquendo MA, Burke AK, Hu XZ, Brent DA, Ellis SP, Goldman D, Mann JJ. Association of a triallelic serotonin transporter gene promoter region (5-HTTLPR) polymorphism with stressful life events and severity of depression. Am J Psychiatry. 2006; 163:1588-1593. [PubMed: 16946185] 
5-HTTLPR genotype

$\square \mathrm{S}^{\prime} \mathrm{S}^{\prime}$

$\square L^{\prime} S^{\prime}$

$\square \mathrm{L}^{\prime} \mathrm{L}^{\prime}$

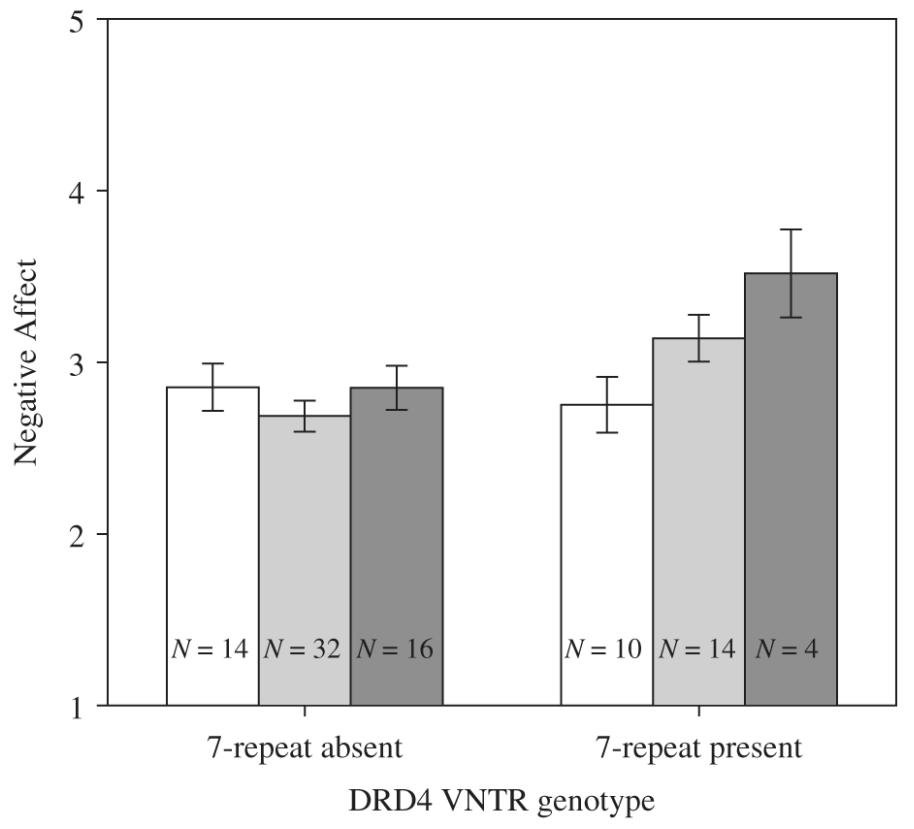

Figure 1. Effect of the 48 base pair variable number of tandem repeats polymorphism in exon 3 of the dopamine D4 receptor gene (DRD4 VNTR) and the serotonin transporter-linked polymorphic region (5-HTTLPR) on Negative Affect in infancy

$\mathrm{S}^{\prime} \mathrm{S}^{\prime}$, low 5-HTT expression group; $\mathrm{L}^{\prime} \mathrm{S}^{\prime}$, intermediate 5-HTT expression group; and $\mathrm{L}^{\prime} \mathrm{L}^{\prime}$, high 5-HTT expression group. 


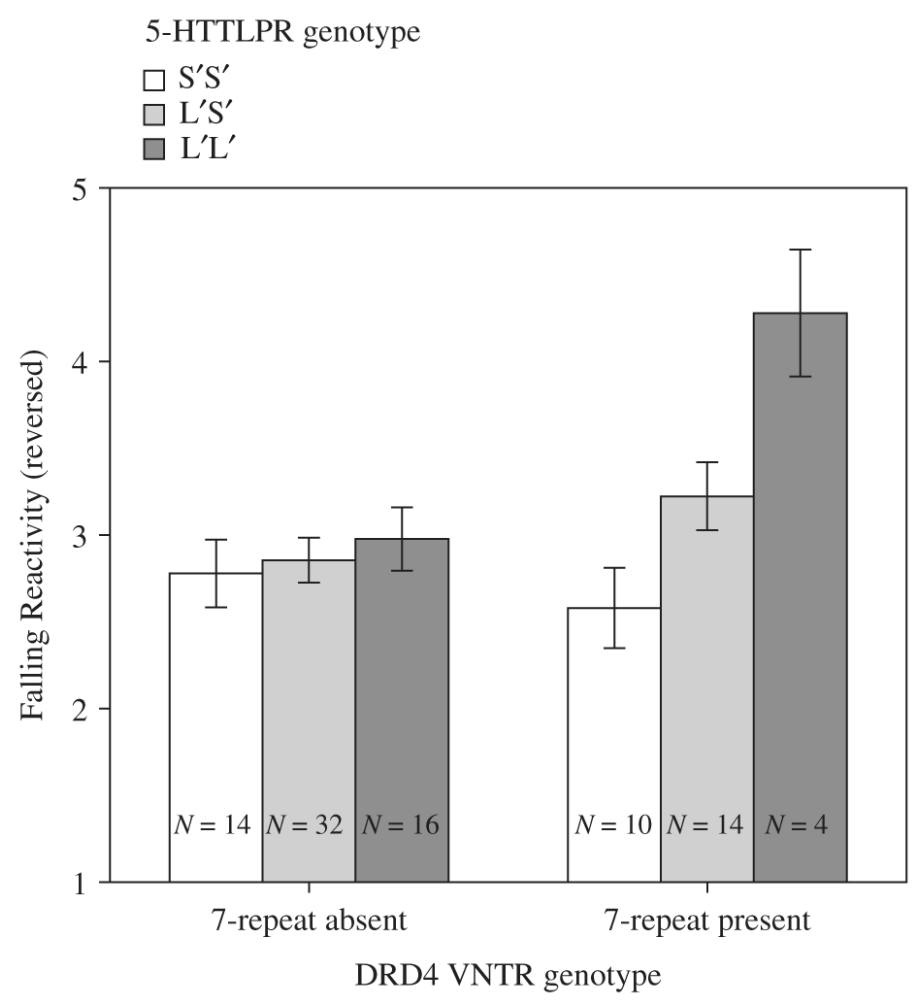

Figure 2. Effect of the 48 base pair variable number of tandem repeats polymorphism in exon 3 of the dopamine D4 receptor gene (DRD4 VNTR) and the serotonin transporter-linked polymorphic region (5-HTTLPR) on Falling Reactivity in infancy

Scores are reversed for easy comparison with Fig. 1. $\mathrm{S}^{\prime} \mathrm{S}^{\prime}$, low 5-HTT expression group; L ' $\mathrm{S}$ ', intermediate 5-HTT expression group; and L' $\mathrm{L}^{\prime}$, high 5-HTT expression group. 


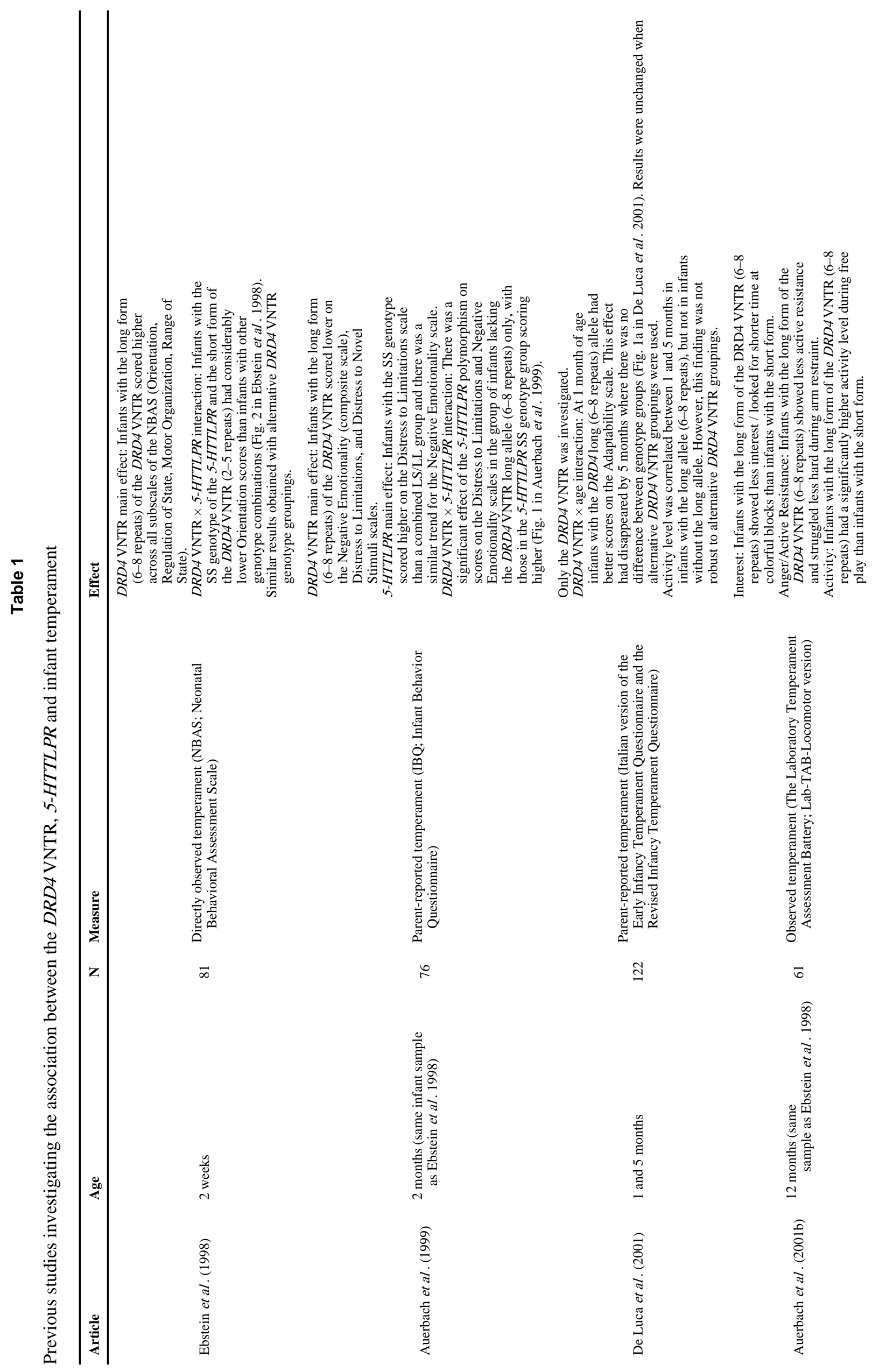



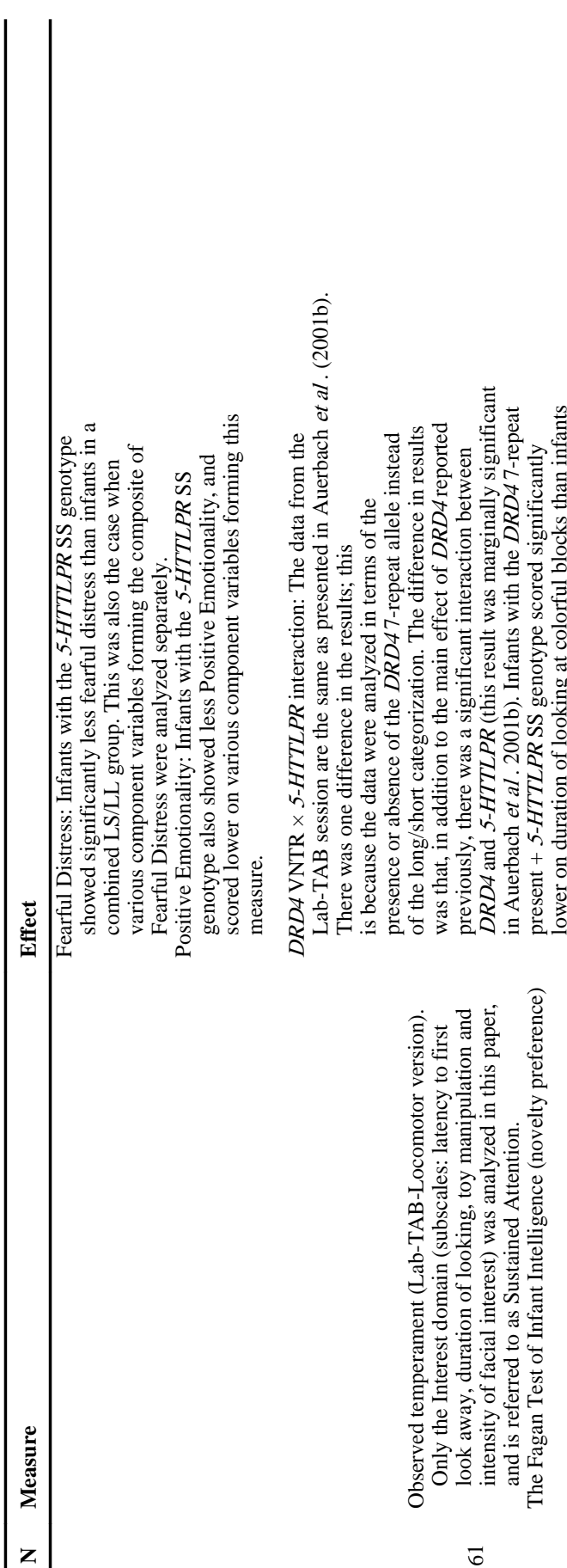

6

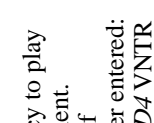

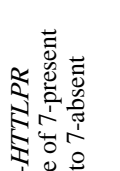

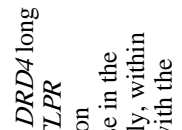

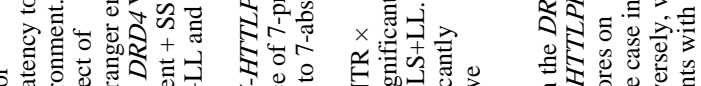
等

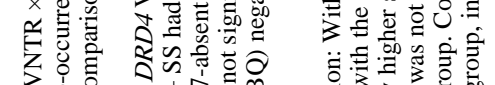
等

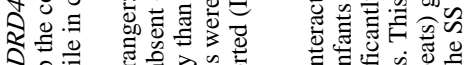

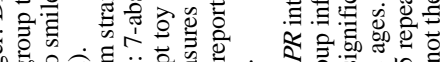

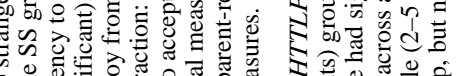

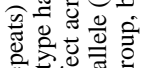

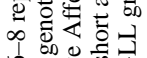

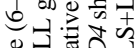

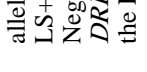
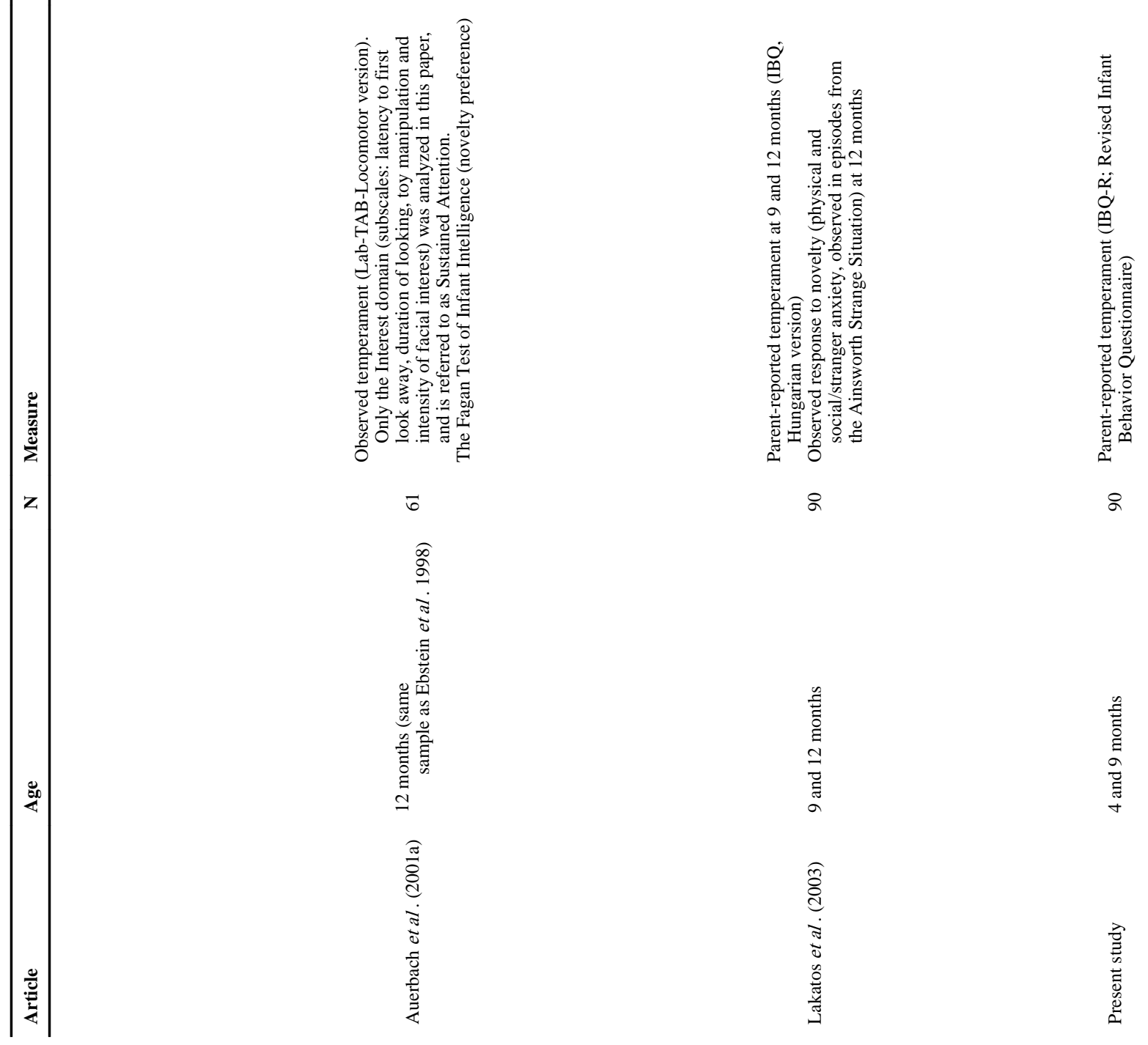

$$
\text { ฉ }
$$$$
\text { \& }
$$

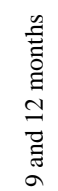

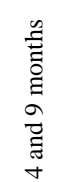

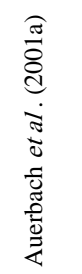

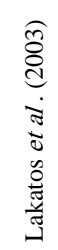




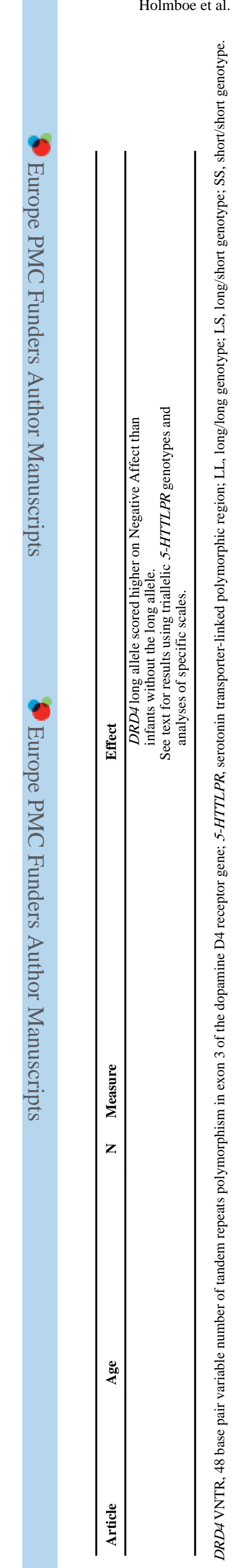


N
$\frac{0}{0}$
$\frac{0}{}$

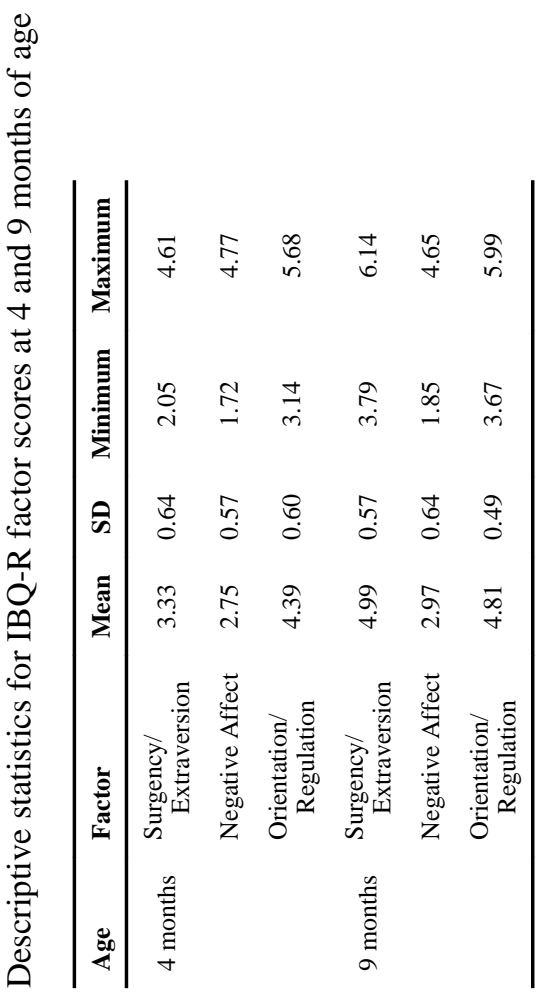

Genes Brain Behav. Author manuscript; available in PMC 2012 February 10. 